\title{
Silane-Based Hybrid Coatings for the Corrosion Protection of AA 2024-T3 Alloy
}

\begin{abstract}
Brenda Diane Pereira Martins ${ }^{1, *}$, Laís de Campos Barbieri ${ }^{1}$, Amanda Alvarenga Coutinho Silva ${ }^{1}$, Naiana Serafim Goulart, Renata Batista Rivero Garcia², Luciana de Simone Cividanes¹, Elizabete Yoshie Kawachi $^{1}$
\end{abstract}

\author{
Martins BDP (iD https: / /orcid.org/0000-0002-1659-403X \\ Barbieri LC (10) https://orcid.org/0000-0002-8108-0406 \\ Silva AAC (1) https://orcid.org/0000-0001-5173-9217 \\ Goulart NS (D) https://orcid.org/0000-0002-5859-672X \\ Garcia RBR (iD https://orcid.org/0000-0001-9391-1177 \\ Cividanes LS (1) https://orcid.org/0000-0001-6932-8619 \\ Kawachi EY (D) https://orcid.org/0000-0002-6477-0886
}

How to cite

\begin{abstract}
Martins BDP; Barbieri LC; Silva AAC; Goulart NS; Garcia RBR; Cividanes LS; Kawachi EY (2019) Silane-based hybrid coatings for the corrosion protection of AA 2024-T3 alloy. J Aerosp Technol Manag, 11, Special Edition: 58-61. https://doi. org/10.5028/jatm.etmq. 75
\end{abstract}

\begin{abstract}
In order to contribute to the corrosion protection of aluminum alloys, silane-based hybrid coatings have been widely studied in the aerospace industry for their good adhesion to aluminum substrates, compatibility with organic paintings and to protect the underlying material, in addition to being much less toxic than the commonly used chromatization process. In this work, hybrid and inorganic sol-gel coatings were evaluated as corrosion inhibitor films for AA2024-T3 alloy. The films were characterized by linear polarization resistance (LPR) and scanning electron microscopy (SEM), which indicated that these coatings provide a lower tendency for the substrate corrosion.
\end{abstract}

KEYWORDS: Sol-gel; Coating; Corrosion resistance; Aluminum alloy.

\section{INTRODUCTION}

Aluminum and its alloys are among the most widely used metallic materials. In the aerospace and automotive sectors, their presence is justified by some of their properties, such as lightness, high fracture toughness, high fatigue performance, high moldability, increased damage tolerance and durability (Santos Junior et al. 2016). However, though aluminum itself has good corrosion resistance, determined by the presence of a natural oxide layer formed on its surface, aluminum alloys show improved mechanical properties, determined by the presence of alloying elements that precipitate in the form of intermetallics and cause localized corrosion. This problem shows up as a consequence of the electrochemical activity difference between the intermetallic precipitate and the aluminum matrix, which is especially high in the case of copper-containing aluminum alloys (Zhang et al. 2017). For these materials, the exceptional, but toxic and carcinogenic, chromatization process has been banned and a potential substitute is the hybrid silane-based coatings obtained from sol-gel process, since it provides good adhesion to aluminum and less environmental damages, with improved corrosion inhibition (Osborne, 2001). Thus, the application of inorganic and hybrid systems obtained by the sol-gel process as corrosion protection coatings for aluminum alloy 2024-T3 is the focus of this study.

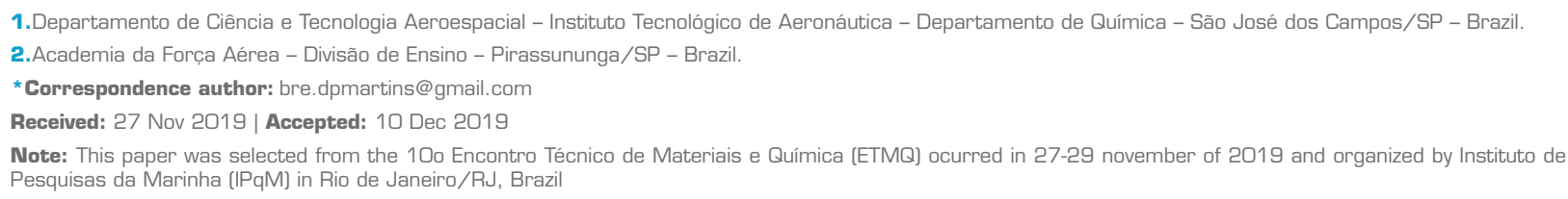




\section{METHODOLOGY}

AA2024 substrates were used in the form of discs, with $\varnothing=35 \mathrm{~mm}$ diameter and $2 \mathrm{~mm}$ thickness. Prior to coating deposition, the substrate surfaces were polished with alumina suspension $(0.3 \mu \mathrm{m})$, applied manually over a disc-shaped polishing cloth $(\varnothing=200 \mathrm{~mm})$ to minimize the natural and passive oxide layer, followed by degreasing with ketone-soaked cotton, according to SSPC-SP1 (2000) and drying at room atmosphere for $10 \mathrm{~min}$.

The inorganic sol-gel system was prepared using tetraethoxysilane (TEOS), ethanol, $\mathrm{HNO}_{3}$, and $\mathrm{H}_{2} \mathrm{O}$, in a molar ratio of 0.27:0.59:0.05:0.46, respectively. For the hybrid compositions, the same parameters were maintained and both precursors, (3-glycidoxy)propyl-trimethoxysilane (GPTMS) and (3-trimethoxysilyl)propyl-methacrylate (TMSPM), were added at a 1:1 molar ratio relative to TEOS. The mixtures were kept for 30 min under an ultrasonic tip action (Hielscher UP $200 S$, $60 \%$ amplitude, and $0.5 \mathrm{~Hz}$ frequency). The whole process was carried out at a temperature of $10^{\circ} \mathrm{C}$, maintained by a thermostatic bath (JULABO GmbH - ME v.2).

The deposition of freshly prepared sol-gel coatings was performed with the aid of a dip coater, with immersion/emersion velocity of $1 \mathrm{~mm} \cdot \mathrm{s}^{-1}$ and $5 \mathrm{~s}$ of rest inside the solution. After the deposition, the substrates were kept under room atmosphere for $24 \mathrm{~h}$ to ensure the complete sol-gel reactions (hydrolysis and condensation) and the solvent evaporation. The linear polarization resistance test was performed using a potentiostat Autolab PGSTAT30, in an electrolytic cell arranged with three electrodes: a reference electrode $(\mathrm{Ag} / \mathrm{AgCl}$, saturated), a working electrode (sol-gel coated and uncoated substrate) and a counter electrode (platinum spiral). The potential window applied was -0.9 to 0.9 (Vref) with a scan rate of 0.001 V.s ${ }^{-1}$. The exposed area evaluated was $0.39 \mathrm{~cm}^{2}$. The electrolyte was a naturally aerated $0.1 \mathrm{~mol} . \mathrm{L}^{-1}$ of $\mathrm{NaCl}$ solution at room temperature. For the morphological characterization of the films and substrate, the Scanning Electron Microscope - SEM Tescan Vegan 3 was used.

\section{RESULTS AND DISCUSSION}

The curves shown in Fig. 1 refer to the linear polarization resistance analysis of uncoated substrates and sol-gel coated substrates, specified as inorganic (TEOS), TEOS/TMSPM hybrid and TEOS/GPTMS hybrid.

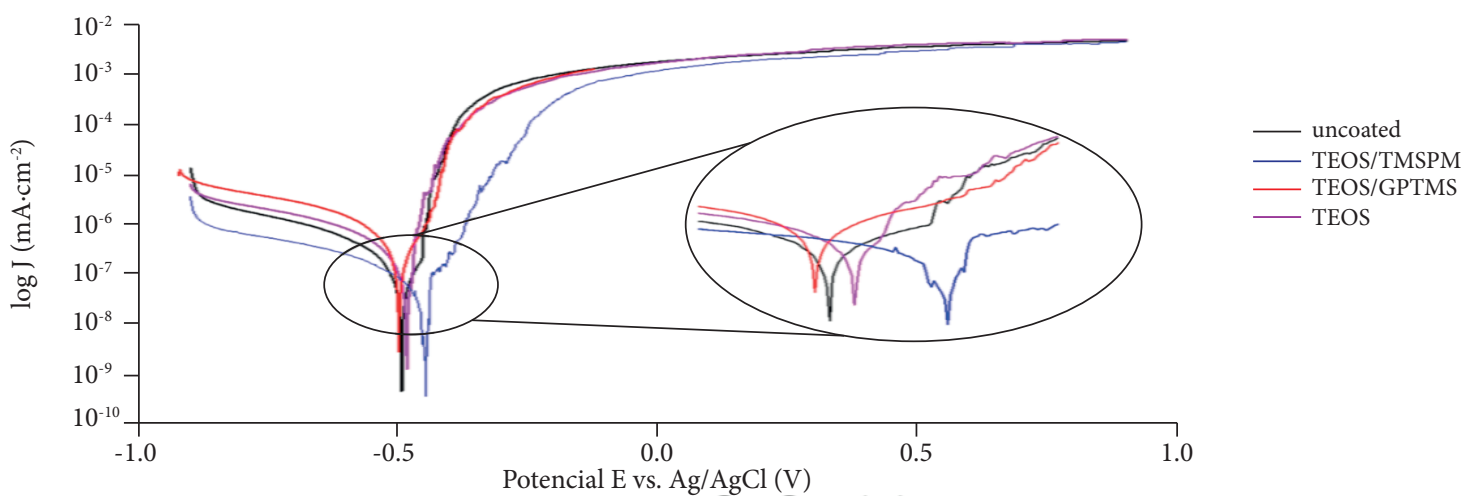

Figure 1. Polarization curves of the uncoated AA2024 substrate and sol-gel coated AA2O24 substrate/TEOS, TEOS/TMSPM and TEOS/GPTMS.

By the Tafel extrapolation method applied to the polarization curves of Fig. 1, the corrosion or pitting potential and current density values, $\mathrm{E}_{\text {corr }}$ and $\mathrm{J}_{\text {corr }}$ respectively, were obtained for each sample, as shown in Table 1.

The corrosion potential represents the thermodynamic tendency of a material to undergo a corrosion process. The more negative the potential, the greater the tendency to corrosion. On the other hand, more positive potential indicates the lower tending to corrosion. 
Table 1. Electrochemical parameters of uncoated AA 2024 substrate and coated AA 2024 substrate with different sol-gel systems.

\begin{tabular}{|c|c|c|}
\hline AA 2024 Substrate & $\mathbf{E}_{\text {corr }}(\mathbf{V})$ & $\mathrm{J}_{\text {corr }}\left(\mathbf{m A}^{\left.\mathbf{A} / \mathbf{c m}^{2}\right]}\right.$ \\
\hline Uncoated & -0.52 & $2.51 \times 10^{-7}$ \\
\hline TEOS sol-gel coated & -0.50 & $2.39 \times 10^{-7}$ \\
\hline TEOS/TMSPM sol-gel coated & -0.44 & $4.07 \times 10^{-8}$ \\
\hline TEOS/GPTMS sol-gel coated & -0.47 & $2.29 \times 10^{-7}$ \\
\hline Standard deviation $(\sigma)$ & 0.03 & $9.98 \times 10^{-8}$ \\
\hline
\end{tabular}

The current density represents the kinetic tendency for oxidation-reduction reactions to occur, thus the increase in the current density increases the charge exchange between the electrodes, favoring corrosion. Thus, it is observed by the polarization curves (Fig. 1) and by the $\mathrm{E}_{\text {corr }}$ and $\mathrm{J}_{\text {corr }}$ values (Table 1) that the hybrid coatings have higher efficiency than the inorganic ones in the protection of AA2024 alloy against corrosion, especially the hybrid TEOS/TMSPM coating, which presented the less negative corrosion potential and the lower current density. Figure 2 shows the morphology of the coatings after the electrochemical assay.

It is possible to observe in the micrographs (Fig. 2) whitish regions present in the uncoated substrate (Figure 2a) that indicates the presence of S phase (Al-Cu-Mg) intermetallic precipitate and the presence of darker spots that indicate the appearance of pitting corrosion (Buchheit et al. 1997), pointed by the circles. The inhomogeneous aspect of the inorganic film (Fig. 2b) is observed by the presence of cracks, indicated by arrows, which enables the contact between electrolyte/substrate and can lead to filiform corrosion points (Gentil 2011). The darker rounded regions observed on the TEOS/TMSPM coating (Fig. 2c), indicated by circles, resemble the presence of pores (Zajícová et al. 2011). Finally, the TEOS/GPTMS coating (Fig. 2d) shows a step between the coated and poorly coated regions, pointed by the arrows.

Though the films presented some defects, none of the coated substrates showed precipitates or pitting corrosion during the electrochemical evaluation, which indicates that the coating adhered to the metal surface protecting it from the medium.
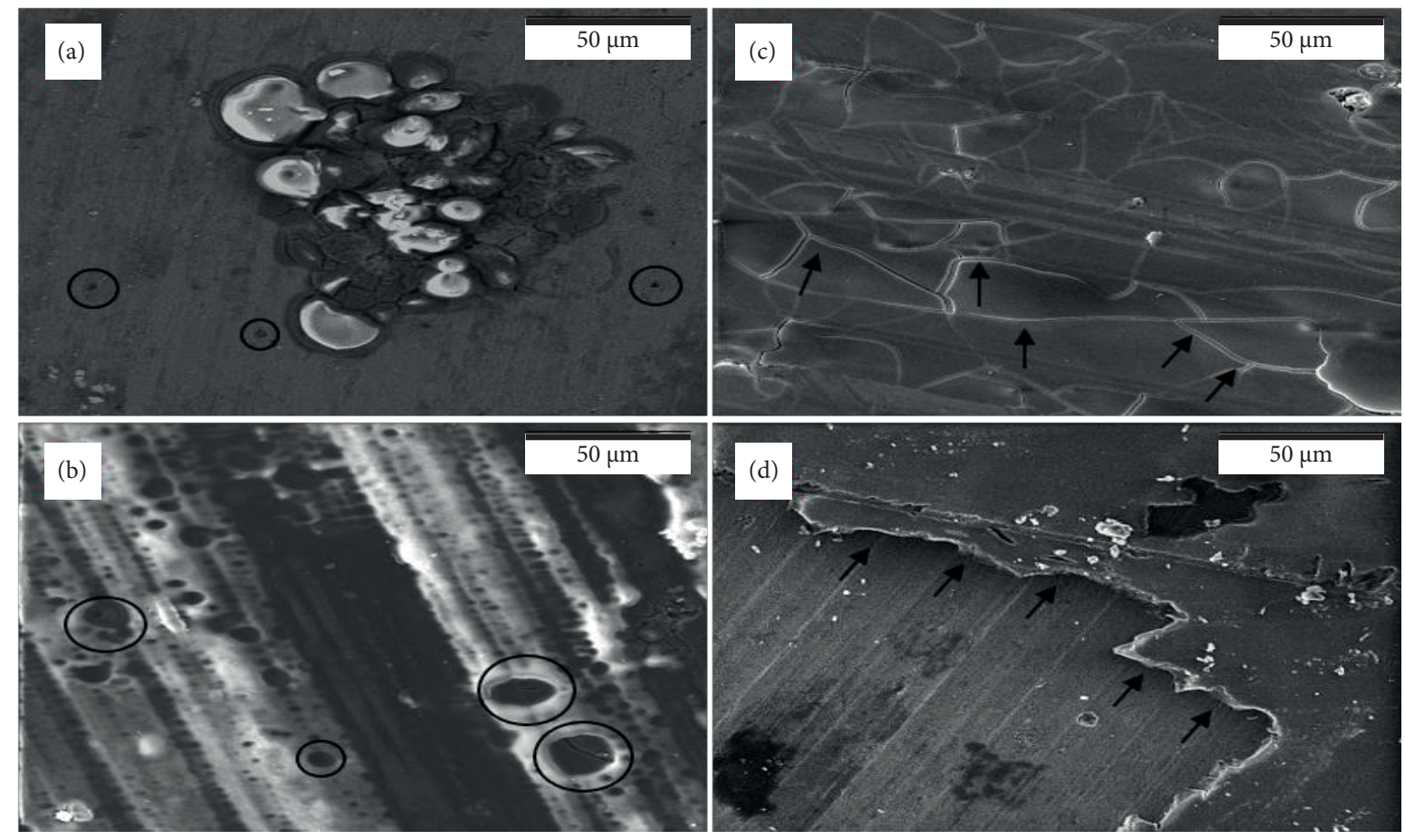

Figure 2. SEM micrographs of the substrate, after linear polarization assay: (a) uncoated; (b) coated with TEOS sol-gel; (c) coated with TEOS/TMSPM sol-gel and (d) coated with TEOS/GPTMS sol-gel. 


\section{CONCLUSION}

By the linear polarization results, the inorganic sol-gel coating contributes insignificantly to both the corrosion potential of the substrate and to its current density, which is attributed to the presence of cracks in the film. On the other hand, the corrosion potentials for the hybrid coatings shifted to more positive values with respect to the uncoated substrate, disfavoring the spontaneity of the oxidative process. The contribution of the TEOS/TMSPM hybrid coating to the noblest potential and the decrease in current density disfavors both the oxidative thermodynamic and kinetic processes. In addition, the hybrid films were more homogeneous than the inorganic one, although none of them showed any indication of corrosion.

\section{FUNDING}

Coordenação de Aperfeiçoamento de Pessoal de Nível Superior [http://doi.org/10.13039/501100002322]

Conselho Nacional de Desenvolvimento Científico e Tecnológico [http://doi.org/10.13039/501100003593]

Grant no 311215/2016-5, 432296/2018-2

Fundação de Amparo à Pesquisa do Estado de São Paulo [http://doi.org/10.13039/501100001807]

Grant n²019/13723-7

\section{AUTHORS' CONTRIBUTION}

Conceptualization, Kawachi EY and Garcia RBR; Methodology, Kawachi EY, Garcia RBR and Cividanes LS; Research, Garcia RBR, Martins BDP, Barbieri LC, Silva AAC and Goulart NS; Writing - First version, Martins BDP and Kawachi EY; Writing Review \& Editing, Martins BDP, Cividanes LS and Kawachi EY; Acquisition of Funding, Cividanes LS and Kawachi EY; Resources, Kawachi EY, Garcia RBR, Martins BDP and Barbieri LC; Supervision, Kawachi EY.

\section{REFERENCES}

[SSPC] Society for Protective Coatings (2000) Surface preparation specification no. 1. Solvent Cleaning. Pittsburgh, USA: SSPC.

Buchheit RG, Grant RP, Hlava PF, Mckenzie B, Zender GL (1997) Local dissolution phenomena associated with S phase (Al2CuMg) particles in aluminum alloy 2024-T3. J Electrochem Soc 144(8):2621-2628. https://doi.org/10.1149/1.1837874

Gentil V (2011) Corrosão. 5th ed. Rio de Janeiro (Brazil): LTC.

Osborne JH (2001) Observations on chromate conversion coatings from a sol-gel perspective. Prog Org Coat 4:280-286. https://doi. org/10.1016/SO300-9440(01)00143-6

Santos Junior MC, Machado AR, Sales WF, Barrozo MAS, Ezugwu EO (2016) Machining of aluminum alloys: a review. Int J Adv Manuf Technol 86(9-12):3067-3080. https://doi.org/10.1007/s00170-016-8431-9

Zajícová V, Exnar P, Staňová I (2011) Properties of hybrid coatings based on 3-trimethoxysilylpropyl methacrylate. Ceram - Silik 55(3):221227.

Zhang X, Zhou X, Hashimoto T, Liu B (2017) Localized corrosion in AA2024-T351 aluminium alloy: Transition from intergranular corrosion to crystallographic pitting. Mater Charact 130:230-236. https://doi.org/10.1016/j.matchar.2017.06.022 